\title{
Epidemiology and Clinical Profile of Male Infertility at the Fertilization Centre IRIFIV in Casablanca, Morocco, around 295 Cases
}

\author{
Modou Mamoune Mbaye ${ }^{1}$, Bouchra El Khalfi ${ }^{1}$, Achraf Zakaria ${ }^{2}$, \\ Brahim Saadani ${ }^{3}$, Noureddine Louanjli ${ }^{2}$ and Abdelaziz Soukri ${ }^{1^{*}}$ \\ ${ }^{1}$ Physiopathology, Molecular Genetics and Biotechnology Laboratory, Ain Chock Faculty of Science, \\ Biology and Center for Health Research, Hassan II University of Casablanca, Morocco. \\ ${ }^{2}$ TyLaboratory of Medical Analyzes, Reproductive Biology, Labomac, Casablanca, Morocco. \\ ${ }^{3}$ In vitro Fertilization Center IRIFIV, IRIS Clinic, Casablanca, Morocco.
}

Authors' contributions

This work was carried out in collaboration among all authors. Author MMM designed the study, performed the statistical analysis, wrote the protocol and wrote the first draft of the manuscript. Authors BEIK, AZ, BS, NL and AS managed the analyses of the study. Author MMM managed the literature searches. All authors read and approved the final manuscript.

Article Information

DOI: 10.9734/ARRB/2019/v32i630106

(1) Dr. Moacir Marocolo, Physiology and Human Performance Research Group, Department of Physiology, Federal University of Juiz de Fora, Brazil.

(2) Dr. Bechan Sharma, Department of Biochemistry, University of Allahabad, Allahabad, India.
Reviewers:

(1) Shigeki Matsubara, Jichi Medical University, Japan.

(2) Juliano Augusto Brum Scheffer, IBRRA, Brazil

(3) Mohammed Ismail Khan, ESIC Medical College, India

Complete Peer review History: http://www.sdiarticle3.com/review-history/50383

Original Research Article

Received 08 June 2019

Accepted 18 August 2019

Published 03 September 2019

\section{ABSTRACT}

Objective: Male infertility is a scourge of the 21st century. Its management remains a real headache. The objective of this study is to describe the general profile of male infertility at the IRIFIV In Vitro Fertilization Center, Casablanca, Morocco.

Materials and Methods: This is a retrospective and descriptive study of 295 patient files seen in consultation for conjugal infertility of the couple between 2017 and 2018. The parameters studied were clinical elements and paraclinical explorations.

Results: The average age of the patients was 37.5 years. The average duration of evolution of 
infertility was 5.5 years. Infertility was primary in $70.9 \%$ of cases and secondary in $29.1 \%$ of cases. Clinically, varicocele was the most common abnormality in $65.9 \%$ of patients. The seminogram was disrupted in $72 \%$ of cases. The main disturbances were oligozoospermia in $40.20 \%$ of cases and asthenozoospermia in $37 \%$ of cases.

Conclusion: The general profile of infertility is polymorphic. The causes of male infertility noted are multifactorial. Male infertility usually results in a quantitative and/or qualitative abnormality of the sperm. The improvement of the management of infertility must go through new ways of research including genetic and immunological for a good identification of usually hidden causes of infertility.

Keywords: Male infertility; sperm; varicocele; in vitro fertilization.

\section{INTRODUCTION}

For a long time, the difficulties in obtaining a pregnancy were systematically attributed to women. But today, this is no longer the case, because male infertility, as an isolated or nonisolated factor, is present in more than $50 \%$ of the infertility of the couple [1]. However, it affects $15 \%$ of couples in the world, approximately 80 million men and women are concerned [2] and is a real public health problem because of its prevalence, generalization, distribution and also the difficulties inherent in its care [3], particularly male infertility affects the Psycho-emotional balance of the couple and by that of society [4], especially in a country like Morocco where procreation is one of the main aims of marriage [5]. This is why non-procreation remains one of the main causes of divorce.

Through this study, it is proposed to identify a general profile of infertility based on the following parameters: clinical examinations, paraclinical examinations, etiologies of male infertility, the different risk factors that may weaken the sperm parameters as well as the frequency of the different seminogram anomalies.

\section{PATIENTS AND METHODS}

The study was conducted at the IRIFIV in vitro fertilization center in Casablanca, Morocco. This is a descriptive and retrospective study of 295 patient records that were followed for marital infertility between 2016 and 2018. Read and informed consent was obtained from all patients included before using their records in this study. The studied parameters were among others epidemiological (age, occupation, risk factors, marital status), clinical (type of infertility, duration of infertility, antecedents, examination data) and paraclinical (seminogram, sperm culture, ultrasound of scrotal contents, infectious test (ECBU, serology, Chlamydia, Mycoplasma and
Ureaplasma by PCR), biopsy testicular in some cases of severe oligozoospermia or azoospermia, determination of $\mathrm{FSH}, \mathrm{LH}$ and testosterone according to the enzyme immunoassay method [6], deferentography in some patients who had a strong suspicion of excretory azoospermia.

\subsection{Collection of Samples}

Sperm samples were collected in sterile containers by masturbation after 3 to 5 days of abstinence [7]. The microscopic analysis was performed using the automated CASA (Computer Assisted Sperm Analysis) method described in World Health Organization (WHO) Standards Fifth Edition, Geneva [8].

\subsection{Statistical Test}

The data were the subject of a statistical study. All graphs and histograms shown in this article were made using the software: GraphPadPrism7.

\section{RESULTS}

\subsection{Age}

Our study involved a cohort of 295 patients. The average age of the patients was 37.5 years with extremes from 25 to 65 years. The age group between 30 and 35 years was the most represented with 83 with a percentage of $28.13 \%$ (Fig. 1). We have the age group between 40 and 45 with a percentage of $22.4 \%$ followed closely by the age group between 45 and 50 which represents $18.30 \%$ of the workforce. Then the age group between 50 and 55 years old constitutes $11.52 \%$, nearly $11.52 \%$ were between 55 and 65 years old and $2.7 \%$ were between 60 and 65 years old. In contrast, the age group between 25 and 30 years of age recorded the lowest percentage at only 1.35 years of age. 


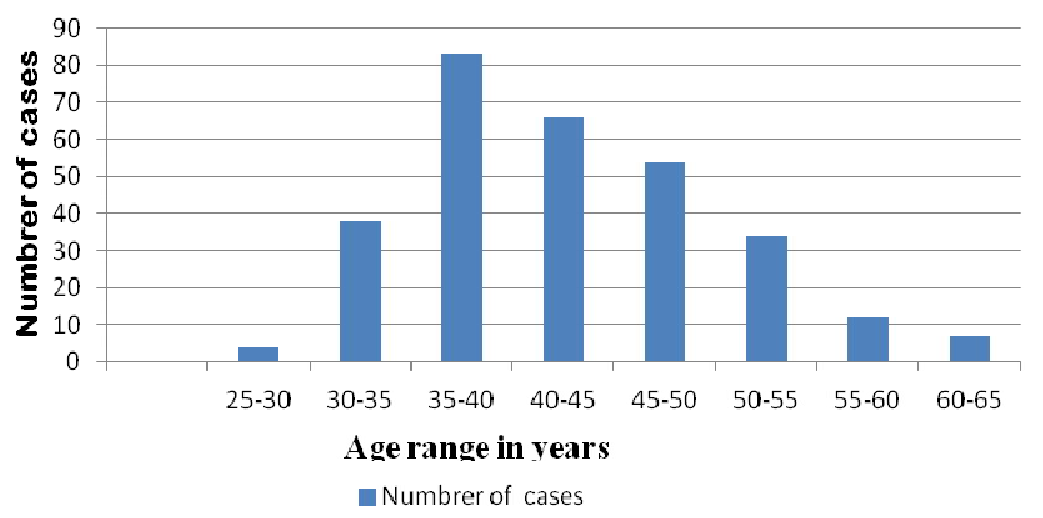

Fig. 1. Distribution of patients by age group in years

\subsection{Type of Infertility}

The two most common types of infertility are primary male infertility with 209 cases out of 295 or $70.9 \%$ and secondary male infertility with 86 cases out of 295 or $29.1 \%$ (Table 1). Primary infertility is defined as a situation where no pregnancy has yet occurred in the couple [9] and secondary infertility resulting from a declared pregnancy, even if it has not been completed or if one of the spouses has already had descendants with another partner [10].

\begin{tabular}{lll}
\multicolumn{2}{|c}{ Table 1. Distribution of patients by type of } \\
infertility \\
& Effective & Percentage (\%) \\
\hline Type of infertility & 209 & 70.9 \\
\hline Primary & 86 & 29.1 \\
Secondary & 295 & 100 \\
\hline Total & \\
\hline
\end{tabular}

\subsection{Duration of Infertility Evolution}

The average duration of male infertility was 5 to 6 years with extremes of 1 to 8 years (Fig. 2).

\subsection{Spermogram}

According to WHO 2010 criteria, the anomalies noted were quantitative and qualitative. The quantitative anomalies were: oligozoospermia in $49.2 \%$ of cases, azoospermia in $37 \%$ of cases. While the qualitative anomalies noted were: asthenozoospermia in $50 \%$ of cases, necrozoospermia in $28 \%$ of cases and teratozoospermia in $34 \%$ of cases (Table 2).

\subsection{Counting in Patients with Varicocele}

The varicocele is a common pathology in the population of infertile men. It is associated with testicular dysfunction and a decrease in the concentration of spermatozoa in the ejaculate.

Table 2. Distribution of patient history

\begin{tabular}{lll}
\hline $\begin{array}{l}\text { Background } \\
\text { information }\end{array}$ & Effective & $\begin{array}{l}\text { Percentage } \\
\text { (\%) }\end{array}$ \\
\hline Orchitis in Mumps & 12 & 40.7 \\
Testicular Trauma & 6 & 2.03 \\
Cryptorchidism & 4 & 1.7 \\
Inguinal hernia cure & 3 & 1.02 \\
Hydrocele cure & 2 & 0.68 \\
Pulmonary tuberculosis 1 & 0.34 \\
\hline
\end{tabular}

\section{DISCUSSION}

The annual number of patients consulting for infertility is increasing more and more. This increase is explained by the increasing interest of populations in their reproductive health. Already in France, more than 60,000 couples consult each year for infertility [11]. In the United States, the number of couples concerned is 6 million [12]. Worldwide, the number of infertile couples is estimated at between 60 and 80 million. About $15 \%$ of couples of childbearing age consult for possible infertility. Although Africa has the highest birth rate in the world, infertility remains a very important sociocultural problem and affects 25 to $40 \%$ of the population with serious social consequences: depression, extramarital sexuality, conflicts. Especially in Morocco, where the purpose of marriage is procreation, which brings joy and harmony to the family [12].

Age is a very important factor in determining the fertility of couples. In our study, the average age of our patients was 37.5 years with extremes ranging from 25 to 65 years old. Our conclusion is in agreement with the data of the literature. Indeed, three studies, two conducted in Senegal in 2008 [13], 2010 [5] and another in Morocco 


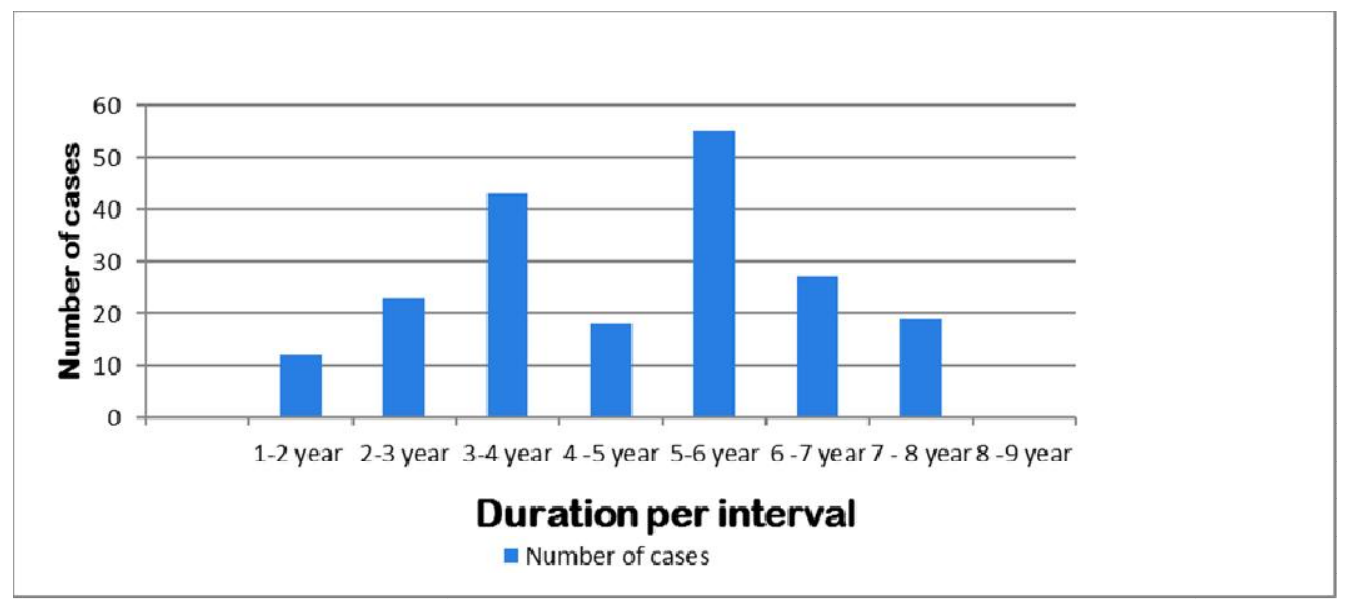

Fig. 2. Distribution of patients by duration of infertility in years

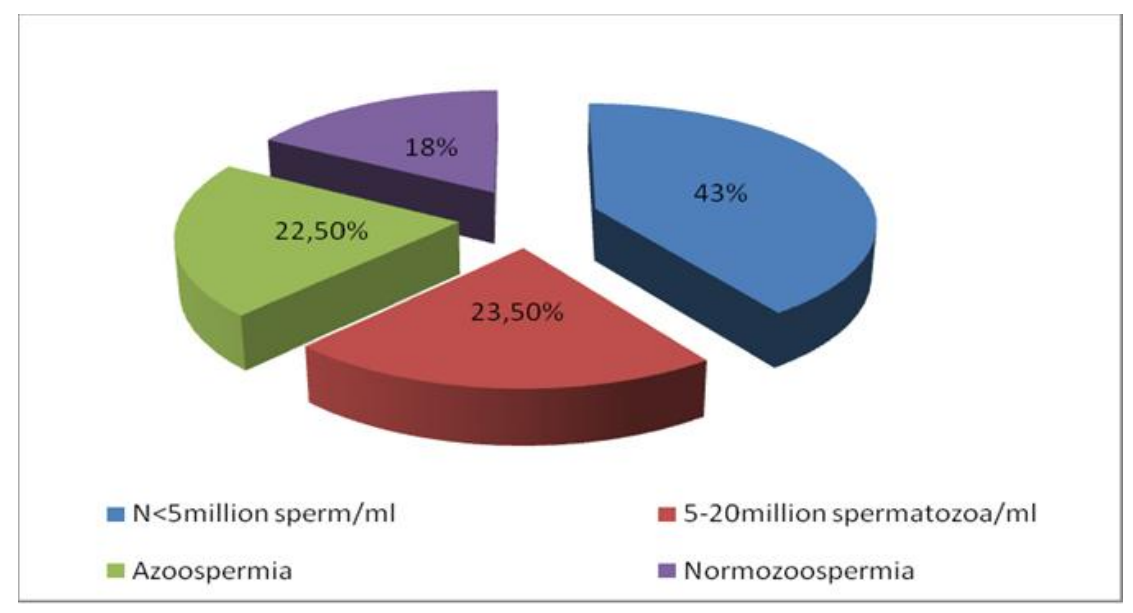

Fig. 3. Distribution of patients by sperm count / $\mathrm{ml}$ in patients with Varicocele

[14], indicate an average age of $39.9,39$ and 37 years respectively, with extremes of 25 . at 50 years old. These results can be explained by certain socioeconomic factors that make marriage more and more late. Meanwhile, biological aging diminishes the fertility potential of individuals, which makes it difficult to conceive couples today [15].

Primary type infertility is the leading cause of consultation. It accounted for $70.9 \%$ of cases. While secondary infertility accounts for $29.1 \%$ of cases. Our results are in perfect correlation with data from the literature such as those of Houssein et al. and Zait et al. respectively in the regions of Fes (Morocco) and Annaba (Algeria). Their results were respectively $75.6 \%$ and $73.48 \%$ for primary type infertility and $24.4 \%$ and $26.53 \%$ for secondary type infertility. According to Thonneau et al. The high rate of primary-type infertility is explained by the frequent tendency of couples without children to consult more than couples with one or more children.

The average duration of infertility was 5.5 years with extremes of 2 to 8 years. The duration of male infertility is in line with data from the literature that indicate average durations of 5.75 years with extremes of 1.5 and 20 years [3], [12].

Occupational risk factors, including stress and environmental pollution, explain the particular representativeness of certain occupations [12]. For the driver profession, particularly exposed to environmental toxins, Thonneau et al. have shown an increase in the average design time for those with a driving time greater than $3 \mathrm{~h} / \mathrm{d}$. In fact, this delay was 4.5 months compared to 
the control group, which had an average of 2.8 months with a significance of $p<0.05$ [3], [11]. For the metallurgical, bakery and cook professions, it has been shown that the temperature of the workstation contributes to the increase of the scrotal temperature, thus contributing to the deterioration of the infertility especially masculine. However, the lack of exposure characterization is a limitation for these studies. Thus, it is necessary to identify the chemical classes and types of radiation involved in this infertility drop [16].

Varicocele was the most common clinical abnormality. These data were far superior to those of other authors who found approximately 20 to $40 \%$ of cases in infertile patients [17]. These disparities are due to a lack of consensus on the actual place of varicocele in male infertility. However, the high percentage of associated testicular atrophy represents a criterion of severity and can be explained by some antecedents found in our patients, but also by other etiologies $[18,19]$.

The alterations noted in the spermograms suggest the same reflection. These may be chromosomal causes, because the lower the number of spermatozoa, the higher the prevalence of chromosomal abnormalities [20]. According to Nang et al. chromosome abnormalities are 3 to $7 \%$ in oligospermia before $13 \%$ in azoospermia [13]. The high rate of azoospermia, especially associated with normal FSH levels, should also search for obstructive causes of infertility. Jarrow et al. Have shown that $\mathrm{FSH}$ levels are approximately 7 to $12 \%$ and are much more common in azoospermia than these normozoosperms [21]. Becker et al. Argue that the main cause of obstructive infertility is bilateral congenital agenesis of the vas deferens, the best diagnostic method of which is endorectal ultrasound [22]. The insignificance of our data on testicular biopsy, hormonology and deferentography, we are not allowed to rule on the actual etiologies of obstructive azoospermia in our region.

The high rate of sexually transmitted infections, which cause stenosis of the seminal tract, is an additional risk factor for these obstructive inferences. Moreover, the infectious balance revealed that infections with chlamydia, mycoplasma and ureaplasma were common in men with subfertility but we did not establish the role of these infections on spermatic parameters [14].

\section{CONCLUSION}

Although current data generally conform to preexisting studies and the existence of new data is scarce. The description of the specific information will contribute to improving health, defining policies and improving education. Because the prevalence of infertility as well as the demand of the patients do not stop increasing due to the event of new risk factors in particular environmental and socioeconomic. Moreover, the presence of centers for medically assisted procreation is proof of this.

\section{CONSENT}

Written informed consent was obtained from all patients included before using their records in this study.

\section{COMPETING INTERESTS}

Authors have declared that no competing interests exist.

\section{REFERENCES}

1. Hammoud AO, Gibson M, Peterson CM, Meikle AW, Carrell DT. Impact of male obesity on infertility: A Critical Review of the Current Literature. Fertil Steril. 2008; 90(4):897-904.

2. Cousineau TM, Domar AD. Psychological impact of infertility. Best Pract Res Clin Obstet Gynecol. 2007;21(2): 293-308.

3. Thonneau $P$, Marchand $S$, Tallec A, Ferial ML, Ducot B, Lansac $J$ and Spira A. Incidence and main causes of infertility in a resident population (1 850 000) of three French regions (1988-1989). Hum Reprod. 1991;6(6):811-816.

4. Jaoul M. The suffering of sterility among men: From objectal to identitaire suffering, how to give support journee SALF Mai; 2013.

5. EL Hajjami $H$. Male infertility: Epidemiological and clinical profile (About 123 cases). Faculty of Medicine and Pharmacy, Fez; 2017.

6. Dul EC, van Ravenswaaij-Arts CMA, Groen $\mathrm{H}$, van Echten-Arends J, Land JA, Tyulenev Y, Klimova R. Poster Viewing session-andrology. Hum Reprod. 2011; 26(suppl_1):i123-i148.

7. Cooper TG, Noonan E, Von Eckardstein S, Auger J, Baker HW, Behre HM et al. World Health Organization reference values for 
human semen characteristics. Hum Reprod Update. 2010;16 (3):231-245.

8. World Health Organisation. WHO laboratory manual for the examination and processing of human semen, Fifth Edition, Genève, WHO. 2010;271.

9. Snick HK, Snick TS, Evers JL, Collins JA. The spontaneous pregnancy prognosis in untreated subfertile couples: The Walcheren primary care study. Hum Reprod (Oxford, England). 1997;12(7): 1582-1588.

10. Thomson E, Winkler-Dworak M, Spielauer M, Prskawetz A. Union instability as an engine of fertility? A microsimulation model for France. Demography. 2012;49(1):175195.

11. Keiding N, Slama R, Ducot B, Blondel B, Bouyer J. The fertility of couples in France. Weekly Epidemiological Bulletin. 2012; (7-8-9):87-91.

12. Westoff CF. Fertility in the United States. Science. 1986;234(4776):554-559.

13. Ndoye M, Niang L, Labou I, Jalloh M, Kane $\mathrm{R}$, Diaw JJ, Gueye SM. Azoospermia in Senegal: What care should be provided at the time of ICSI? Andrology 2008;18(3): 206.

14. Meng Q, Ren A, Zhang L, Liu J, Li Z, Yang $Y$, Ma L. Incidence of infertility and risk factors of impaired fecundity among newly married couples in a Chinese population.
Reprod Biomed Online. 2015;30(1): 92-100.

15. Cherlin A. Marriage, divorce, remarriage. Harvard University Pressp; 2009.

16. Oberdörster G, Maynard A, Donaldson K, Castranova V, Fitzpatrick J, Ausman K, Olin S. Principles for characterizing the potential human health effects from exposure to nanomaterials: Elements of a screening strategy. Particle and fibre toxicology. 2005;2(1):8.

17. Macleod J. Seminal cytology in the presence of varicocele. Fertility and Sterility.1965;16(6):735-757.

18. Aafjes $\mathrm{JH}$, Van der Vijver JC. Fertility of men with and without varicocele. Fertil Steril.1985;43:901-904.

19. Sigman M, Jarrow JP. Ipsilateral testicular hypotrophy is associated with decreased sperm counts in infertile men with varicoceles. J. Urol.1997;158:605-607.

20. Reteif AE, Van Zyl JA, Menkveld R. Chromosome studies in 496 infertile males with a sperm count below $10 \mathrm{million} / \mathrm{ml}$. Hum Genet. 1984;66:162-164.

21. Jarrow JP, Espeland MA, Lipshultz. Evaluation of the azoospermic patient. J. Urol.1989;142:62-65.

22. Belker AM, Steinbock GS. Transrectal prostate ultrasonography as a diagnostic and therapeutic aid for ejaculatory duct obstruction. J. Urol. 1990;144:356-358.

(C) 2019 Mbaye et al.; This is an Open Access article distributed under the terms of the Creative Commons Attribution License (http://creativecommons.org/licenses/by/4.0), which permits unrestricted use, distribution, and reproduction in any medium, provided the original work is properly cited.

Peer-review history:

The peer review history for this paper can be accessed here: http://www.sdiarticle3.com/review-history/50383 